\title{
Knowledge and Use of Modern Contraception among Muslim Women in Zaria, Nigeria
}

\author{
Sa'adatu T. Sule, M.B., B.S., M.P.H., F.W.A.C.S., Hajara Suleiman Umar, M.B., B.S., \\ Nana Hawwa Madugu, M.D.
}
Department of Obstetrics and Gynaecology, Ahmadu Bello University Teaching Hospital, Zaria, Nigeria

Abstract

Objective: To determine the knowledge and use of modern contraceptives among Muslim women in Zaria, Nigeria and recommend ways to increase uptake thus reducing maternal morbidity and mortality related to high parity.

Methods: 200 Muslim women in Zaria were interviewed between August 1 and October 31, 2003.

Results: Majority (92.5\%) had some knowledge about modern contraceptives but only $9 \%$ knew $>3$ methods and hospitals were their most common source of information. The rate of previous contraceptive use was $21 \%$ while current use was $13 \%$. Unmet need for contraception was $7.5 \%$ mainly due to fear of side effects (60\%) and husband's disapproval (26.7\%). Contraception was believed to be unIslamic by $16 \%$ of the women. of the women who had Islamic education alone, $58.1 \%$ believed that contraception was unIslamic $(p=0.04)$.

Conclusion: There is inadequate knowledge of modern contraceptives and misconceptions exist about the position of Islam on contraception. Muslim women and men, and Islamic leaders and teachers should be adequately informed on these issues.

Key Words: Contraception, Muslim women, Nigeria

Introduction

Islam permits the use of contraception provided that there are strong reasons for it based on the personal circumstances of couples, and provided that they are used for a good cause, and result in no harm. ${ }^{1}$

However, misconceptions about the position of Islam on contraception exist, with many Muslims believing that Islam opposes contraception. ${ }^{2-5}$ Efforts are being made to correct such misconceptions in many Muslim countries with varying degrees of success. Although

Correspondence: Dr. Sa'adatu T. Sule Ipas Nigeria, 2nd Floor Katsina House, Ralph Shodeinde Street, Central Area, Abuja, Nigeria.

Email: saasule@yahoo.com the use of modern contraceptives has increased in many Muslim populations ${ }^{6,7}$, the fertility rate among Muslim women is still higher and the contraceptive prevalence is still lower compared with non-Muslim women even within the same country. 3,4,8-10 This may be due to the poor educational status among Muslim women $n^{4,6,9,11,12}$ or may result from inadequate knowledge of modern contraceptive methods and misconceptions about them among Muslim women. ${ }^{13,14}$ Other factors that have been suggested as contributing to the higher fertility rates among Muslim women include earlier age at marriage $e^{8,9,15}$ and polygyny, which may lead to pregnancy rivalries. ${ }^{16}$ In addition, Muslims may view the advocacy for contra- 
ceptive use by Western countries with suspicion because they regard it as a means of keeping Muslim populations low in order to weaken them.3,17

Over 50\% of Nigeria's total population are Muslims. The largest Muslim populations live in the less economically developed northern part of the country. ${ }^{17,18}$ The total fertility rate in northern Nigeria is 6.6 compared to 4.5 in the south while the maternal mortality rate is about 1,287 per 100,000 live births in the north compared to about 225 per 100,000 live births in the south. Similarly, the prevalence of modern contraceptive use among married women is $5.3 \%$ in the north and $12.5 \%$ in the south with a national average of $9 \% .19$ The main causes of maternal mortality include problems arising from high parity and inadequate birth spacing, such as hemorrhage, which accounts for almost a quarter of all maternal deaths in Nigeria. ${ }^{19}$ This study was carried out to document the knowledge and beliefs of Muslim women in a northern Nigerian town and their contraceptive practices with a view to finding ways to improve the contraceptive uptake among these women. This will help to decrease the incidence of problems due to high parity and inadequate pregnancy spacing.

\section{Methods}

Two hundred Muslim women attending the Gynecology and Antenatal clinics of the Ahmadu Bello University Teaching Hospital and the Muslim Specialist Hospital, both located in Zaria, northern Nigeria, were interviewed between August 1, 2003 and October 31, 2003. Two female Obstetrics and Gynecology residents conducted the interviews using a structured questionnaire after obtaining consent from the women. Open-ended questions were used to obtain information about knowledge of con- traceptives and methods used previously or currently. Rates and comparative analyses were carried out on the data using MINITAB statistical software. Statistical tests of association included the Student's t-test, chi-squared tests and $95 \%$ confidence intervals. The level of significance used for all the tests was $<0.05$.

For the purpose of this study, 'Islamic education' was used to refer to formal Islamic schooling which may be undertaken either on full-time or part-time basis and last for several years. The curricula for these schools are fairly uniform and include Qur'ānic recitation, memorization and interpretation, Islamic history, Hadith (Prophet Muhammad's sayings, PBUH) and Figh (Islamic jurisprudence). The semiformal and informal Qur'anic schools that teach only Qur'ānic recitation and memorization are very common and the vast majority of northern Nigerian Muslims are exposed to this type of Islamic education to some extent, especially during childhood. This less formal type of schooling is not included as Islamic education in this study.

\section{Results}

The mean age of the women was 28.2 years ( $S D=$ 7.29 , range $=17$ to 45$)$. The mean parity was $3.4(S D=$ 2.75 , range $=0$ to 13 ). $17.6 \%$ were nulliparous, $50.2 \%$ had a parity of 1 to 4 , and $32.2 \%$ were grandmultiparous. The mean age at first marriage was $\mathbf{1 7 . 2}$ years $(S D=3.35$, range $=12$ to 29 ).

Table 1 shows the marital status, marriage order and educational status of respondents. Most of the study women 168 (91.3\%) were housewives. Six (3.3\%) were students and four (2.2\%) were teachers. There were one $(0.5 \%)$ each trader, nurse, pharmacist, tailor, civil servant and security woman.

Table 1: Social Characteristics of Respondents

\begin{tabular}{|l|l|l|l|}
\hline Educational Status & Number (\%) & Marital Status & Number (\%) \\
\hline None & $18(9)$ & Married & $199(99.5)$ \\
\hline Primary & $46(23)$ & Widowed & $1(0.5)$ \\
\hline Secondary & $45(22.5)$ & Marriage Order & Number (\%) \\
\hline Tertiary & $19(9.5)$ & First & $176(88)$ \\
\hline Islamic only & $69(34.5)$ & Second & $17(8.5)$ \\
\hline Primary and Islamic & $2(1)$ & Third & $5(2.5)$ \\
\hline Tertiary and Islamic & $1(0.5)$ & Fourth & $1(0.5)$ \\
\hline & & Sixth & $1(0.5)$ \\
\hline
\end{tabular}


Table 2: Knowledge of various modern contraceptive methods

IUCD = intra-uterine contraceptive device, BTL = bilateral tubal ligation

\begin{tabular}{|l|l|l|l|l|}
\hline & Know (\%) & Don't know (\%) & Previous use (\%) & Current use (\%) \\
\hline Pills & $178(89.9)$ & $20(10.1)$ & $9(21.4)$ & $3(11.5)$ \\
\hline Injectables & $159(80.3)$ & $39(19.7)$ & $22(52.4)$ & $13(50)$ \\
\hline IUCD & $16(8.1)$ & $182(91.9)$ & $6(14.3)$ & $5(19.2)$ \\
\hline Norplant & $33(16.7)$ & $165(83.3)$ & $4(9.5)$ & $4(15.4)$ \\
\hline Condoms & $73(36.9)$ & $125(63.1)$ & $0(0)$ & $0(0)$ \\
\hline BTL & $10(5.1)$ & $188(94.9)$ & $1(2.4)$ & $1(3.8)$ \\
\hline
\end{tabular}

Table 3: Previous and current use of various modern contraceptives IUCD = intra-uterine contraceptive device. BTL = bilateral tubal ligation.

\begin{tabular}{|l|c|c|c|c|}
\hline Method & \multicolumn{2}{|c|}{ Previous use $(\mathrm{n}=42)$} & \multicolumn{2}{c|}{ Current use $(\mathrm{n}=26)$} \\
\hline & Number & Percentage & Number & Percentage \\
\hline Pills & 9 & 21.4 & 3 & 11.5 \\
\hline Injectables & 22 & 52.4 & 13 & 50.0 \\
\hline IUCD & 6 & 14.3 & 5 & 19.2 \\
\hline Norplant & 4 & 9.5 & 4 & 15.4 \\
\hline Condoms & 0 & 0 & 0 & 0 \\
\hline BTL & 1 & 2.4 & 1 & 3.8 \\
\hline
\end{tabular}

Only $9 \%$ of the women knew more than 3 methods of contraception and none mentioned male sterilization as a contraceptive method. There were 42 women (21\%) who had used a modern method of contraception previously and 26 women (13\%) who were currently using a modern contraceptive.

Details are shown in Tables 2 and 3.

There was no significant association between knowledge of the various contraceptive methods and the age, age at marriage, parity of the women or the number of previous marriages they had, as shown in Table 4.

The hospital was mentioned as the source of contra- ceptive information by a total of $87.5 \%$ of all respondents, the radio by $29 \%$, friends/relations by $7 \%$, books by $6.5 \%$, school by $1.5 \%$, and television by $0.5 \%$. Details are shown in Table 5.

Of the 21 women who responded to the question on why they discontinued use of contraceptives, $47.5 \%$ discontinued use because they wanted another pregnancy, $47.5 \%$ gave side effects as the reason and $5 \%$ (1 woman) got pregnant while using a contraceptive method.

Twelve women did not respond to a question about whether they wanted to use contraceptives. Of the remaining $188,50(26.6 \%)$ said they would like to use contraceptives but only 26 of these were using con-

Table 4: $\mathrm{P}$ values for tests of association between knowledge of various contraceptive methods and variables of interest

*Student's t-test. ${ }^{* *}$ Chi-square test. IUCD = intra-uterine contraceptive device. $\mathrm{BTL}=$ bilateral tubal ligation

\begin{tabular}{|l|c|c|c|c|}
\hline Method & Mean age* & $\begin{array}{c}\text { Mean age at } \\
\text { marriage* }\end{array}$ & Parity** & $\begin{array}{c}\text { Previous } \\
\text { marriage** }\end{array}$ \\
\hline Pills & 0.99 & 0.82 & 0.31 & 0.05 \\
\hline Injectables & 0.48 & 0.83 & 0.15 & 0.18 \\
\hline IUCD & 0.05 & 0.05 & 0.45 & 0.65 \\
\hline Norplant & 0.28 & 0.09 & 0.46 & 0.93 \\
\hline Condoms & 0.78 & 0.72 & 0.73 & 0.11 \\
\hline BTL & 0.39 & 0.05 & 0.42 & 0.74 \\
\hline
\end{tabular}


Table 5: Source of contraceptive information among 200 respondents

\begin{tabular}{|c|c|c|c|}
\hline Source & Number (\%) & Source & Number (\%) \\
\hline Hospital alone & $122(6 \mathrm{I})$ & School & $1(0.5)$ \\
\hline Hospital and radio & $36(18)$ & Hospital and school & $1(0.5)$ \\
\hline Radio alone & $12(6)$ & Hospital, school and friends or relations & $1(0.5)$ \\
\hline Friends or relations & $11(5.5)$ & Hospital and friends or relations & $1(0.5)$ \\
\hline Hospital, radio and books & $9(4.5)$ & Radio and friends or relations & $1(0.5)$ \\
\hline Hospital and books & $4(2)$ & Hospital and television & $1(0.5)$ \\
\hline
\end{tabular}

traceptives. Of the 24 women who were not using contraceptives, 10 were pregnant and said they would use a modern contraceptive method after delivery. The reasons for non-use by the other 14 women included fear of side effects (9), fear of husband's reaction (4), and lack of funds (1). Out of the 188 women who answered the question, 133 (70.7\%) said they would not like to use contraceptives while the remaining 5 (2.7\%) said they did not know whether they would like to use contraceptives or not.

Reasons for not wanting to use contraceptives were the desire for future pregnancy ( 60 or $45.1 \%$ ), the belief that contraception is unIslamic (32 or 24.1\%) and the husband's disapproval (20 or 15\%). Other reasons were the fear of side effects ( 3 or $2.3 \%$ ), belief that they had no need for contraception due to naturally well-spaced deliveries ( 3 or 2.3\%), belief that contraception was immoral ( 1 or $0.7 \%$ ), and desire for at least 10 children ( 1 or $0.7 \%$ ). The other 13 women (9.7\%) did not give a reason for not wanting to use contraceptives.
There were 32 women who believed that contraception was unIslamic. Of these, 19 (58\%) had only Islamic education, one (3.2\%) had no education at all and 12 (38.7\%) had other forms of education alone or in combination with Islamic education. The proportion of women who felt that contraception was unIslamic was significantly higher among the 69 women who had only Islamic education (27.5\%) compared to those with no education (5.5\%) and those with other forms of education (10.6\%), $p=0.04$ (chi squared $=6.45$ ).

The mean age was significantly higher for previous or current contraceptive users compared to nonusers while the mean age at marriage was not significantly different for previous or current contraceptive users compared to non-users. Details are shown in Tables 6 and 7.

A lower proportion of previous or current contraceptive users were nulliparous (2.1\% and $0 \%$ respectively) while a higher proportion were grandmulti-

Table 6: Association between previous and current contraceptive use and mean age

\begin{tabular}{|l|l|l|l|}
\hline & $\begin{array}{l}\text { Mean } \\
\text { age } \\
\text { (years) }\end{array}$ & $\begin{array}{l}95 \% \\
\text { confidence } \\
\text { intervals }\end{array}$ & P value \\
\cline { 1 - 2 } Previous use & 31.7 & $2.2,6.7$ & $<0.001$ \\
\cline { 1 - 2 } No previous use & 27.2 & & 0.006 \\
\cline { 1 - 2 } Current use & 32.2 & $1.4,7.6$ & 0 \\
\cline { 1 - 2 } No current use & 27.7 & & \\
\hline
\end{tabular}

Table 7: Association between previous and current contraceptive use and mean age at marriage

\begin{tabular}{|l|c|c|c||}
\hline & $\begin{array}{c}\text { Mean age at } \\
\text { marriage (years) }\end{array}$ & $\begin{array}{c}95 \% \text { confidence } \\
\text { intervals }\end{array}$ & P value \\
\cline { 1 - 2 } Previous use & 17.5 & $-0.8,1.7$ & 0.5 \\
\cline { 1 - 2 } No previous use & 17.1 & $-1.8,1.5$ & 0.86 \\
\hline Current use & 17.0 & & \\
\hline No current use & 17.2 & & \\
\hline
\end{tabular}


Table 8: Association between previous and current contraceptive use and variables of interest

\begin{tabular}{||l|c|c|c|c|}
\hline \multirow{2}{*}{} & \multicolumn{2}{|c|}{ Previous contraceptive use } & \multicolumn{2}{c|}{ Current contraceptive use } \\
\cline { 2 - 5 } & $\chi^{2}$ value & P value & $\chi^{2}$ value & P value \\
\hline Parity & 12.06 & 0.002 & 7.96 & 0.02 \\
\hline $\begin{array}{l}\text { Previous } \\
\text { abortions }\end{array}$ & 0.63 & 0.730 & 0.34 & 0.84 \\
\hline Education & 21.14 & 0.002 & 3.65 & 0.72 \\
\hline Occupation & 2.97 & 0.560 & 3.85 & 0.43 \\
\hline $\begin{array}{l}\text { Information } \\
\text { source }\end{array}$ & 11.29 & 0.420 & 11.58 & 0.40 \\
\hline $\begin{array}{l}\text { Previous } \\
\text { marriage }\end{array}$ & 1.12 & 0.890 & 1.21 & 0.88 \\
\hline $\begin{array}{l}\text { Marriage } \\
\text { type }\end{array}$ & 0.21 & 0.880 & 0.75 & 0.39 \\
\hline
\end{tabular}

parous ( $46.8 \%$ and $50 \%$ respectively). These differences were statistically significant as shown in Table 8.

Women who had tertiary education had the highest proportion of previous or current users $(52.6 \%$ and 21.1\% respectively) compared to those who had no education (14.3\% and $14.3 \%$ respectively), primary education (8.9\% and $6.7 \%$ respectively), secondary education (29.5\% and $15.9 \%$ respectively) or Islamic education ( $26.6 \%$ and $15.9 \%$ respectively). The differences were statistically significant for previous use but not for current use as shown in Table 8. There was still no statistical association between education and current contraceptive use after controlling for current pregnancy, which could be a confounding factor (chi-squared $=3.60, p=0.61$ ). There was no association between previous and current contraception use and type of marriage (polygynous vs. monogynous), previous marriage, information source, occupation or history of previous abortions.

\section{Discussion}

The mean parity in this study (3.4) was lower than the total fertility rate for the northwestern zone (6.5) of Nigeria ${ }^{19}$ in which Zaria is located, most likely due to hospital bias. These women were hospital patients attending the clinics for various reasons including infertility and many of them had not yet stopped childbearing, both of which may explain the lower mean parity than expected.

Multiple marriages contribute to high parity and low contraceptive usage as women are expected to bear children for their new husbands but there was no association between the number of marriages and contraceptive use in this study, possibly because the majority of the women (87.8\%) were in their first marriage. Polygynous marriages may also contribute to high parity and poor acceptance of contraceptives as women compete with each other ${ }^{16}$ to prove their worth by having many children. Polygyny may not play a very important role in this area because although $37.9 \%$ of the women were in polygynous marriages, there was no significant association between previous or current contraceptive use and type of marriage.

The majority of the women had some knowledge of modern contraceptive methods, but only $9 \%$ were able to mention more than three methods. None mentioned vasectomy as a contraceptive method, probably viewing contraception as entirely a woman's affair. Poor knowledge of contraceptive methods and their side effects are important limiting factors to contraceptive use.,5,9,13 The fact that the most common source of information about contraceptives was the hospital is not unexpected as women often come into contact with contraceptive information from health care providers during pregnancy and childcare visits.16,17 The radio was the source of information for many of these women and could be an important alternative for providing reproductive health information to women who do not utilize health care facilities. Up to $40.4 \%$ of women in this area listen to the radio daily. ${ }^{19}$ 
The most popular modern contraceptive method among both previous (52.4\%) and current (50\%) users was the injectables, most likely due to the fact that they ensure privacy and do not interfere with coitus. This finding is unexpected among Muslim women as the injectables are frequently associated with irregular bleeding that disrupts prayers and sexual intercourse. ${ }^{5}$

Education was significantly associated with previous contraceptive use as has been reported previously. 4,6,8,9,11,12 Education delays the age at first pregnancy by delaying the age at first marriage and increases women's understanding of reproductive health issues leading to greater likelihood of contraceptive use, both resulting in fewer and betterspaced births.

The unmet need for contraception in this study was $7 \%$. More than half of the women who had unmet need cited fear of side effects as a reason though they had never used any modern contraceptive method and their perceptions were based on myths, reflecting the poor knowledge of contraceptives among Muslim women as has been reported previously. ${ }^{13,14}$ The second most common reason for unmet need was husbands' disapproval, probably an indication of inaccurate information among Muslim men in this environment about modern contraceptives, the position of Islam about their use, or both. Similar findings were reported previously from Egypt. ${ }^{14}$

Many of the women (24.4\%) who did not want to use contraceptives believed that contraception was unIslamic and the majority (58.1\%) of those who felt this way were those who had Islamic education only. These findings suggest that misconceptions exist in this population about the position of Islam on contraception. The fact that these misconceptions are common among women who had Islamic education may be due to Islamic schools not teaching women about reproductive health issues or due to these women being given incorrect information by teachers who lack accurate information or are biased.

This study suggests lack of accurate information among Muslim women and men in Zaria, about modern contraceptives and the position of Islam on their use. Muslims need to be aware of the position of Islam concerning contraception and the uses and side effects of modern contraceptive methods. Training is required for reproductive health workers and Islamic teachers and leaders on reproductive health issues within the context of Islam so that they can communicate correct information to the general populace. Islamic schools catering for adults, especially married women, should be encouraged to provide their students with such information. Muslims need the opportunity to make informed decisions about their reproductive health without feeling that they are jeopardizing their spiritual well being. Lower parity and adequate birth spacing, in addition to improved education of women, improved standard of living, and adequate, accessible and affordable health care services will help to minimize maternal morbidity and mortality among Muslim women in this environment.

\section{References}

1. Tantawi MS. The religious view of birth control. Cairo, International Islamic Center for Population Studies and Research 1988, Al Azhar University, pp. 12 and 32.

2. Saghayroun AA, Khalifa MA. Fertility and Islam in the Sudan. Sudan J Popul Stud 1984; 1(2):1-28.

3. Kats G. Family planning and the religious issue. Cairo Today 1983 Jan;4(1):43-4.

4. Quraishi SY. Muslims' low practice of family planning, India. Low levels of education, particularly among women, is one of the major reasons behind high fertility rates. Integration 1996 Spring;47:23-7. 5. Ghazal-Aswad S, Rizk DE, Al-Khoori SM, Shaheen $\mathrm{H}$, Thomas L. Knowledge and practice of contraception in United Arab Emirates women. J Fam Plann Reprod Health Care. 2001 Oct;27(4):212-6.

6. Roudi N. The demography of Islam. Popul Today. 1988 Mar;16(3):6-9.

7. Hassanein MK. Indicators and patterns of reproductive health in the Muslim world. In: Serour GI, editor. Proceedings of the International Conference on Population and Reproductive Health in the Muslim World, February 21-24, 1998. Cairo: Al-Azhar University: 311-24.

8. Abu Ahmed A, Tabenkin H, Steinmetz D. Knowledge and attitudes among women in the Arab village regarding contraception and family planning and the reasons for having numerous children. (English abstract only). Harefuah. 2003;142(12):822-5, 
$879,878$.

9. Tafforeau J, Damiba A, Maternowska MC. Changes in Chad: the results of a KAP survey. Biol Soc. 1990 Dec;7 (4):194-202.

10. Oheneba-sakyi Y. Socio-economic and cultural differentials in contraceptive usage among Ghanaian women. Int J Sociol Fam Autumn. 1990;20(2):139-61. 11. Sufian AJ. Determinants of contraceptive knowledge and family planning services in Bangladesh. Genus 1992; 48 (3-4): 119-28.

12. Ahmad S. Effect of education on marital fertility in four Muslim populations. Genus. 1985;41(1-2):2337.

13. Albsoul-Younes AM, Saleh F, El-Khateeb W. Perception of efficacy and safety as determinants for use and discontinuation of birth control methods in Muslim Jordanian women. Eur J Contracept Reprod Health Care. 2003 Sep;8(3):156-61.

14. Tantawy AB, Hassan FI. Study of unmet need of family planning and response to health education among women at reproductive age. Popul Sci. 2001;
25:51-64.

15. Isiugo-Abanihe UC, Ebigbola JA, Adewuyi AA. Urban nuptiality patterns and marital fertility in Nigeria. J Biosoc Sci. 1993 Oct;25(4):483-98. 16. Sargent C, Cordell D. Polygamy, disrupted reproduction, and the state: Malian migrants in Paris, France. Soc Sci Med 2003 May;56(9):1961-72. 17. Olurode L. Impact of social change on reproductive choice in Nigeria: A study of Muslim women in purdah. In: Serour GI, editor. Proceedings of the International Conference on Population and Reproductive Health in the Muslim World, February 21-24, 1998. Cairo: Al-Azhar University: 346-59.

18. Lecky M. Nigeria. Spotlight. Popul Today. 1984;12 (12):16.

19. NPC/UNICEF. Children's and Women's Rights in Nigeria: A Wake-up Call. Situation Assessment and Analysis 2001. Abuja, Nigeria: National Planning Commission (NPC) and UNICEF, 2001. 